\title{
间作小麦光合性能对地上地下互作强度的响应
}

王一帆殷文胡发龙范虹牀志龙赵财于爱忠柴 强* 甘肃省干旱生境作物学重点实验室 / 甘肃农业大学农学院, 甘肃兰州 730070

摘 要: 本研究旨在探讨地上地下互作强度对间作小麦光合性能的影响, 为进一步揭示间作体系作物产量优势的光 合机制提供依据。2015-2017 年连续 3 年在河西绿洲灌区进行田间试验，以小麦间作玉米为研究对象，设置地下部 3 种互作强度: 根系不分隔(完全地下互作处理, W/M)、300 目尼龙网分隔(部分地下互作处理, NW/M)和 $0.12 \mathrm{~mm}$ 塑料 布分隔(无地下互作处理, PW/M), 以及地上部高、低玉米密度(M1、M2) 2 种互作强度, 同时设置相应单作处理。结 果表明, 小麦间作玉米共生前期和后期完全地下互作处理促使小麦净光合速率 $\left(P_{\mathrm{n}}\right)$ 显著提高, 且共生后期玉米密度 的提高促使完全地下互作效应增强, 进一步提高了小麦 $P_{\mathrm{n}}$ 。小麦间作玉米共生前、中和后期, 完全地下互作处理可 显著提高小麦叶片气孔导度 $\left(G_{\mathrm{s}}\right)$ 、胞间 $\mathrm{CO}_{2}$ 浓度 $\left(C_{\mathrm{i}}\right)$, 且玉米密度提高对共生前期完全地下互作处理和部分地下互作

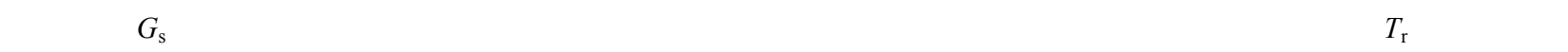
地下互作处理有助于小麦叶日积(LAD)的增加, 且随着生育进程的推进, 提高比率越大。完全地下互作处理使共生中 期间作小麦叶片相对叶绿素含量值(SPAD)显著增加, 有利于光合强度的提高。间作小麦具有显著的增产效应, 完全 地下互作处理中小麦籽粒产量达到相应单作产量的 $76.8 \%$, 具有显著提高间作群体籽粒产量的优势, 且地上部互作 强度增强有利于完全地下互作处理正效应的发挥。地上地下互作强度是影响间作小麦光合性能的重要因素之一, 在 生产实践中可通过调节地上地下互作强度的强弱来优化低位作物光合性能。

关键词：间作；地上地下互作强度；小麦；光合性能；产量

\section{Response of photosynthetic performance of intercropped wheat to interaction intensity between above- and below-ground}

\author{
WANG Yi-Fan, YIN Wen, HU Fa-Long, FAN Hong, FAN Zhi-Long, ZHAO Cai, YU Ai-Zhong, and CHAI \\ Qiang*
}

Gansu Provincial Key Laboratory of Arid Land Crop Science / College of Agronomy, Gansu Agricultural University, Lanzhou 730070, Gansu, China

\begin{abstract}
The purpose of this study is to explore the effects of above-ground and underground interaction intensity of intercropped population on the photosynthetic performance of intercropped wheat and to provide a basis for further revealing the photosynthetic mechanism of crop yield advantage in intercropping system. From 2015 to 2017 wheat intercropping with maize was taken as the research object. Three root separation methods were designed: no root separation (complete below-ground interaction treatment, W/M), 300 mesh nylon net separation (partial below-ground interaction treatment, NW/M), $0.12 \mathrm{~mm}$ plastic cloth separation (no below-ground interaction treatment, PW/M), and tow level maize densities. Meanwhile, the corresponding monocluture was carried out. The results showed that the $P_{\mathrm{n}}$ of intercropped wheat was significantly increased by the complete below-ground interaction treatment during per-symbiotic period and late symbiotic period of wheat/maize intercropping, with the increase of maize density the $P_{\mathrm{n}}$ of wheat increased during late symbiotic period. During per-symbiotic period, mid-symbiotic period and late symbiotic period of wheat/maize intercropping, the complete below-ground interaction treatment can significantly improve the $G_{\mathrm{s}}, C_{\mathrm{i}}$ of intercropped wheat. The increase of maize density can promote the increase of $G_{\mathrm{s}}$ in the complete
\end{abstract}

本研究由国家自然科学基金项目(31771738)和甘肃农业大学伏羲青年人才培育项目(Gaufx-03Y10)资助。

This study was supported by the National Natural Science Foundation of China (31771738) and the Fuxi Young Talents Fund of Gansu Agricultural University (GaufX-03Y10).

*通信作者(Corresponding author): 柴强, E-mail: chaiq@gsau.edu.cn

第一作者联系方式: E-mail: wangyf@gsau.edu.cn

Received (收稿日期): 2020-06-08; Accepted (接受日期): 2020-11-13; Published online (网络出版日期): 2020-12-22.

URL: https://kns.cnki.net/kcms/detail/11.1809.S.20201222.1648.007.html 
below-ground interaction treatment and partial below-ground interaction treatment during per-symbiotic period. The $T_{\mathrm{r}}$ of leaves was higher during mid-symbiotic period and late symbiotic period of wheat/maize intercropping without below-ground interaction treatment, while the $T_{\mathrm{r}}$ of leaves remained lower in both stages of complete below-ground interaction and partial below-ground interaction. Complete below-ground interaction treatment was helpful to increase the daily leaf area (LAD) in wheat, with the development of growth process, the increase ratio was larger. Complete belowground interaction treatment significantly increased the SPAD of leaves during mid-symbiotic period, which was beneficial to increase photosynthetic intensity. Intercropped wheat had significant yield-increasing effect. The grain yield of wheat under complete below-ground interaction treatment reached $76.8 \%$ of the corresponding single-cropped, which had the advantage of significantly increasing the grain yield of intercropping population. Moreover, the enhancement of above-ground interaction intensity was conducive to the positive effect of complete below-ground interaction treatment. The intensity of above- and below-ground interaction was one of the important factors affecting the photosynthetic characteristics of intercropped wheat.

Keywords: intercropping; above- and below-ground interaction intensity; wheat; photosynthetic performance; yield.

间作是两种或者两种以上的作物分行或分带种 植在同一块田地里，具有集约利用光、热、肥、水 等自然资源的优势 ${ }^{[1-2]}$ 。间作群体冠层受光结构优于 单作, 由平面受光转向立体显著提高了作物受光区 域和受光时间, 实现了作物对光的分层立体利用 ${ }^{[3]}$ 。 然而间作种植模式中不同作物组合之间存在空间垂 直差异时, 位于中下层的低位作物冠层则处于弱光 胁迫中 ${ }^{[4-5]}$ 。因此研究低位作物的光合特性和产量规 律, 对进一步提升间作系统产量有重要的应用价 值。地上地下部互作是间作增产的重要原因之一 ${ }^{[6-7]}$, 各组分地上部与地下部生态位发生分离, 在时间和 空间上扩大, 使得作物冠层能充分利用光能, 地下 部根系空间分布扩大, 互补利用水分、养分等资源 ${ }^{[8]}$ 。 但地上、地下互作强度对间作低位作物光合性能影 响机制尚不明确, 使得在生产实际中缺乏理论依 据。研究表明地上地下部完全互作可显著提高小麦 玉米间作优势, 地上部密度增加可进一步提高地下 部互作对间作优势的贡献率，而且通过增密和根系 完全互作可提高间作群体叶日积和间作组分净光合 速率 ${ }^{[6]}$ 。间作群体冠层结构呈伞状, 能够有效提高高 位作物净光合速率, 而低位作物遮阴有利于叶绿素 含量的增加, 提高弱光时的光能利用效率 ${ }^{[9]}$ 。研究表 明, 与单作大豆相比, 玉米和大豆间作栽培模式使 大豆的光合速率日变化呈单峰曲线, 弱化了大豆的 光合午休现象, 玉米花生间作提高了 2 种作物叶片 的叶绿素含量, 燕麦/大豆和燕麦/花生间作模式中, 净光合速率分别提高 $0.9 \%$ 42.9\%和 $3.4 \% \sim 37.2 \%$, 同时间作燕麦的相对叶绿素含量显著高于单作 ${ }^{[10]}$ 。 但有报道指出地上种间作用对增强间作花生利用弱 光的贡献为负效应, 地下种间作用为正效应 ${ }^{[11]}$, 间 作遮阴导致了花生植株徒长、叶片净光合速率、气 孔导度和蒸腾速率降低, 碳代谢酶活性降低, 进而 影响单株饱果数、百果重, 最终降低荚果产量 ${ }^{[12-13]}$ 。
小麦间作玉米系统中，小麦处于光能截获的劣势， 地上地下互作强度的增加是否对间作小麦的光合性 能起到促进作用, 对产量的影响如何尚不明确。本 研究在河西走廊绿洲灌区以典型小麦间作玉米为研 究对象, 设置不同地上地下互作强度, 在之前研究 基础上进一步对组分作物小麦光合生理特性分析, 明确低位作物小麦光合性能响应地上地下互作强度 的机制, 为进一步揭示间作群体产量优势的光合机 制提供依据。

\section{1 材料与方法}

\section{1 试区概况}

试验于 2015-2017 年连续 3 年在甘肃省武威市 黄羊镇甘肃农业大学试验基地 $\left(37^{\circ} 30^{\prime} \mathrm{N}, 103^{\circ} 5^{\prime} \mathrm{E}\right)$ 进 行。试验区位于河西走廊东端, 属寒温带干旱气候 区, 年平均气温 $7.2^{\circ} \mathrm{C}, \geq 10^{\circ} \mathrm{C}$ 积温为 $2985.4^{\circ} \mathrm{C}$; 多 年平均降雨量为 $156 \mathrm{~mm}$, 年日照时数 $2945 \mathrm{~h}$, 无霜 期 $155 \mathrm{~d}$, 属于典型的一季不足, 两季有余的自然生 态区, 适宜发展多熟种植。试区土壤为典型的灌漠 土, $0 \sim 30 \mathrm{~cm}$ 土壤全氮 $0.68 \mathrm{~g} \mathrm{~kg}^{-1}$ 、全磷 $1.41 \mathrm{~g} \mathrm{~kg}^{-1}$ 、 有机质 $14.31 \mathrm{~g} \mathrm{~kg}^{-1}$ 。

\section{2 试验设计}

采用随机区组试验设计, 设置小麦间作玉米地 下部 3 种互作强度: 根系不分隔 $(\mathrm{W} / \mathrm{M}$, 地下部完全 互作)、300 目尼龙网分隔(NW/M, 地下部分互作)和 $0.12 \mathrm{~mm}$ 塑料布分隔 $(\mathrm{PW} / \mathrm{M}$, 无地下互作), 地上部 2 种互作强度: 根据当地常用玉米种植密度设置间作 低玉米密度水平 $\left(4.50\right.$ 万株 $\mathrm{hm}^{-2}$ )和高玉米密度水平 (5.25 万株 $\mathrm{hm}^{-2}$ ), 共 6 个间作处理。同时设置相应 的单作处理, 单作小麦 $(\mathrm{W})$ 和 2 个密度水平的单作玉 米( M1 和 M2), 单作玉米密度分别为 10.5 万株 $\mathrm{hm}^{-2}$ 和 9.0 万株 $\mathrm{hm}^{-2}$, 单作共 3 个处理, 共计 9 个处理, 每处理重复 3 次, 田间布置图如图 1。 


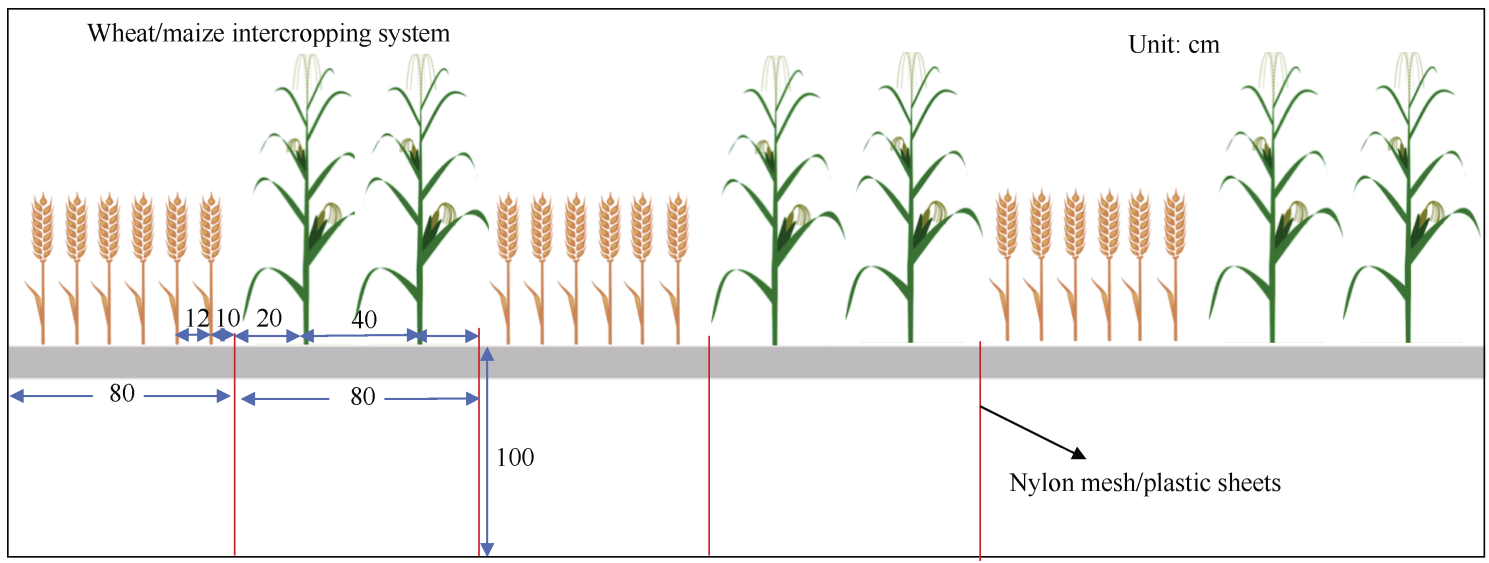

图 1 小麦间作玉米隔根示意图

Fig. 1 Schematic diagram of wheat/maize intercropping and root separation

两种作物带宽均为 $80 \mathrm{~cm}$, 玉米种 2 行(行距 $40 \mathrm{~cm}$ ), 小麦种 6 行(行距 $12 \mathrm{~cm}$ ), 3 种隔根方式为不隔根、尼龙网隔根和塑料布隔根, 试 验开始前，在间作两种作物中间开沟，将隔根材料垂直隔至土壤 $100 \mathrm{~cm}$ 处。

Field layout of wheat/maize intercropping with a strip of $80 \mathrm{~cm}$ of wheat crops (six rows) alternated with a strip of $80 \mathrm{~cm}$ of maize crops (two rows), without physical barrier, with a nylon mesh, and with a solid plastic sheet, between wheat and maize strips. Plastic sheet and nylon mesh were placed vertically to the depth of $100 \mathrm{~cm}$ to separate the rooting zones between the two intercrops.

供试小麦品种为宁春 2 号, 玉米品种为先玉 335 。2015 至 2017 年小麦播种日期分别为 3 月 29 日、3 月 28 日和 3 月 25 日，收获日期分别为 7 月 27 日、7 月 21 日和 7 月 25 日; 玉米播种日期分别 为 4 月 25 日、 4 月 23 日和 4 月 21 日，收获日期分 别为 9 月 28 日、9 月 25 日和 9 月 25 日。

\section{3 测定指标}

1.3.1 净光合速率、气孔导度、胞间 $\mathrm{CO}_{2}$ 浓度和蒸 腾速率在小麦间作玉米共生前期(小麦拔节 期)、小麦间作玉米共生中期(小麦抽穗期)以及小麦 间作玉米共生后期(小麦灌浆期)，使用美国 Li-Cor 公司生产的 Li-6400 型便携式光合系统测定仪，选 择晴朗无风的天气上 9:00一-11:30, 每小区随机选 取 15 株小麦连续 $3 \mathrm{~d}$ 测定小麦净光合速率、气孔导 度、胞间 $\mathrm{CO}_{2}$ 浓度和蒸腾速率, 每叶片重复 3 次后 取均值, 各时期的测定值取 $3 \mathrm{~d}$ 平均值。

\subsection{2 相对叶绿素值(SPAD) 在小麦间作玉米} 共生前期(小麦拔节期)、小麦间作玉米共生中期(小 麦抽穗期)以及小麦间作玉米共生后期(小麦灌浆期), 使用 SPAD 仪测定小麦旗叶叶绿素含量, 每小区随 机选取 15 株小麦, 连续测定 $3 \mathrm{~d}$, 每叶片重复 3 次后 取均值，各时期的测定值取 $3 \mathrm{~d}$ 平均值。

\subsection{3 叶日积 用下公式求得:}

$$
\mathrm{LAD}=\sum_{i=1}^{n}\left(\mathrm{LAI}_{i} \times D_{i}\right)
$$

式中, $\mathrm{LAI}_{i}$ 为第 $i$ 个生育阶段的平均叶面积, $D_{i}$ 为第 $i$
个生育阶段所持续的时间。其中 LAI 由下公式求得:

$$
\mathrm{LAI}=k \times \rho \sum_{i=1}^{n}\left(a_{i} \times b_{i}\right)
$$

式中, $k$ 取值 $0.83, \rho$ 为小麦栽培密度, $a 、 b$ 分别为叶 片的长和宽, $i$ 为叶片数。在各生育时期随机选 15 株 样测定小麦叶片长、宽。

\subsection{4 籽粒产量和收获指数籽粒产量和生物产} 量均在作物成熟后, 以小区为单位收获、计产。用 PM-8188 谷物水分仪测定籽粒含水率, 重复 5 次后 取其平均。收获指数是籽粒产量和生物产量的比值。

\section{4 统计分析}

采用 Microsoft Excel 2016 整理、汇总数据, 采 用 SPSS 17.0 进行显著性分析 (Duncan's multiple range tests $P<0.05$ )、主效应检验及互作效应分析。

\section{2 结果与分析}

2.1 地上地下互作强度对小麦光合生理指标的 影响

2.1 .1 净光合速率 $\left(P_{\mathrm{n}}\right)$ 小麦抽穗期单作小麦 $P_{\mathrm{n}}$ 与间作差异不显著, 在开花期达到最高, 单作较间 作高 $18.1 \%$ (图 2); 灌浆期, 间作较单作 $P_{\mathrm{n}}$ 显著提高 $37.0 \%$ 。单作小麦在花期有较高的 $P_{\mathrm{n}}$, 但在灌浆期显 著降低，因此，间作较单作在小麦生长后期可保持 较高的 $P_{\mathrm{n}}$ 。

间作中, 小麦间作玉米共生前期(小麦抽穗期) 玉米密度对小麦 $P_{\mathrm{n}}$ 影响差异不显著, 间作地下互作 
强度影响差异显著，二者互作差异不显著，年际间 差异显著(图 2)。2015 年和 2016 年完全地下互作处 理的小麦 $P_{\mathrm{n}}$ 较无地下互作处理分别高 $48.9 \%$ 和 $85.5 \%, 2016$ 年和 2017 年完全地下互作较部分地下 互作处理 $P_{\mathrm{n}}$ 分别提高 $71.3 \%$ 和 $34.3 \%$, 部分地下互 作较完全地下互作处理无显著差异。小麦间作玉米 共生中期(小麦开花期), 玉米密度和地下互作强度 对小麦 $P_{\mathrm{n}}$ 的影响差异均不显著。小麦间作玉米共生 后期(小麦灌浆期), 玉米密度和地下互作强度对小 麦 $P_{\mathrm{n}}$ 影响差异均显著, 二者互作不显著, 年际间差
异显著。2016 年和 2017 年完全地下互作处理较无 地下互作处理小麦 $P_{\mathrm{n}}$ 分别提高 $15.6 \%$ 和 $48.4 \%$, 部 分地下互作较无地下互作处理分别提高 $26.6 \%$ 和 $12.3 \%$ ，完全地下互作较部分地下互作处理无显著 差异。地下完全互作处理下高玉米密度处理较低密 度 3 年平均提高小麦 $P_{\mathrm{n}} \quad 10.7 \%$, 其他处理下玉米密 度对小麦 $P_{\mathrm{n}}$ 影响差异不显著。因此，完全地下互作 处理有利于小麦 $P_{\mathrm{n}}$ 在小麦玉米共生前期和后期提高, 玉米密度在共生后期对完全地下互作处理下小麦 $P_{\mathrm{n}}$ 起到促进作用。

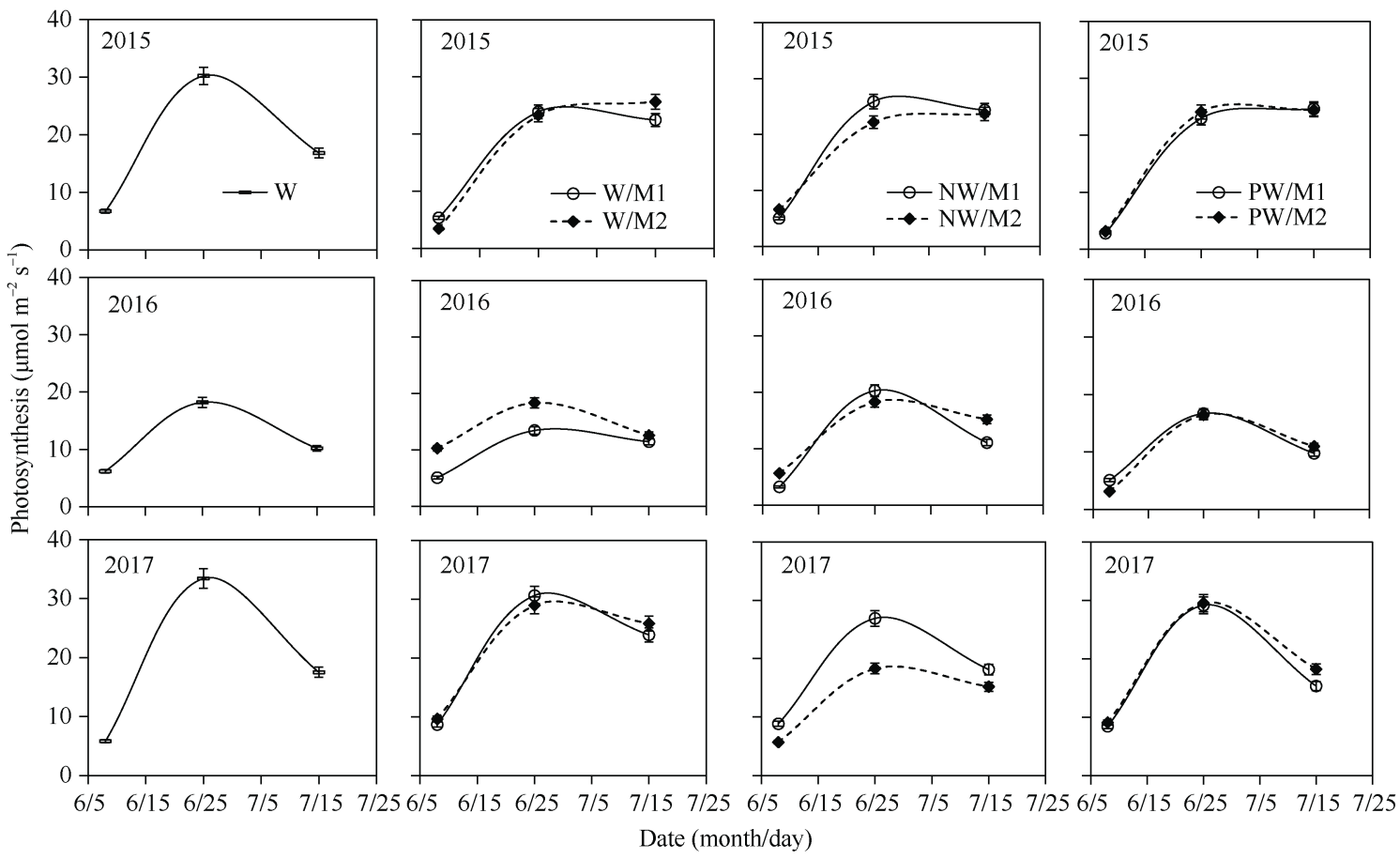

图 2 不同地上地下互作强度下间作小麦净光合速率时间动态

Fig. 2 Temporal dynamics of photosynthetic rate of intercropped wheat under different above- and below-ground interaction intensities

$\mathrm{W}$ : 单作小麦; $\mathrm{M} 1$ : 低密度单作玉米; M2：高密度单作玉米; $\mathrm{N}$ : 尼龙网隔根; $\mathrm{P}$ ：塑料布隔根。误差线为标准误差。

W: sole wheat; M1: sole maize in low density; M2: sole maize in high density; N: nylon mesh barrier; P: plastic sheet barrier. The error bars indicate standard errors.

\subsection{2 气孔导度 $\left(G_{\mathrm{s}}\right)$ 小麦 $G_{\mathrm{s}}$ 在抽穗期最高, 随} 后呈下降趋势，与单作相比，在抽穗期间作小麦 $G_{\mathrm{s}}$ 提高 $86.1 \%$ ，开花期提高 $112.5 \%$ ，灌浆期降低 90.8\% (图 3)。说明间作可显著提高小麦抽穗期和开花期的 $G_{\mathrm{s}}$, 而降低灌浆期的叶片 $G_{\mathrm{s} 。}$

间作中，小麦间作玉米共生前期，玉米密度和 地下互作强度对小麦叶片 $G_{\mathrm{s}}$ 的影响差异显著，二者 互作显著, 年际间差异显著(图 3)。取 3 年平均值, 完 全地下互作处理较部分地下互作和无地下互作处理 的小麦叶片 $G_{\mathrm{s}}$ 分别提高 $44.6 \%$ 和 $141.0 \%$, 部分地下 互作处理较无地下互作处理提高 $70.4 \%$ 。完全地下
互作处理下, 玉米高密度较低密度处理在 2015 年和 2016 年分别使小麦叶片 $G_{\mathrm{s}}$ 提高 $28.7 \%$ 和 $44.8 \%$, 部 分地下互作处理下，高密度较低密度在 2015、2016 和 2017 年分别提高 $46.8 \% 、 81.4 \%$ 和 $27.2 \%$, 无地下 互作处理下密度对 $G_{\mathrm{s}}$ 影响差异不显著。说明小麦玉 米共生前期，间作完全地下互作可显著提高小麦叶 片 $G_{\mathrm{s}}$, 玉米密度的增加对完全地下互作和部分地下 互作下小麦 $G_{\mathrm{s}}$ 的增加均起到正效应。小麦间作玉米 共生中期, 玉米密度对小麦 $G_{\mathrm{s}}$ 影响差异不显著, 地 下互作强度影响显著, 年际间差异不显著。完全地 下互作处理较部分地下互作和无地下互作处理小麦 
叶片气孔导度分别提高 $74.4 \%$ 和 $26.4 \%$, 部分地下互 作处理与无地下互作处理间无显著差异。说明共生 中期完全地下互作是提高小麦气孔导度的原因之 一。小麦间作玉米共生后期, 玉米密度对小麦气孔 导度影响差异不显著, 地下互作强度影响差异显著, 二者无互作，年际间差异不显著。完全地下互作和 部分地下互作处理较无地下互作处理小麦叶片 $G_{\mathrm{s}}$ 分 别提高 $36.6 \%$ 和 $69.2 \%$, 部分地下互作较完全地下互 作处理显著提高 $24.0 \%$ 。说明共生后期完全地下互 作和部分地下互作处理均有利于叶片 $G_{\mathrm{s}}$ 的增加, 但完全地下互作处理的提高幅度小于部分地下互 作处理。

2.1.3 胞间 $\mathrm{CO}_{2}$ 浓度 $\left(C_{\mathrm{i}}\right)$ 小麦 $C_{\mathrm{i}}$ 浓度呈先上升 后下降趋势(图 4), 与单作相比, 间作在抽穗期、开 花期和灌浆期均使小麦 $C_{\mathrm{i}}$ 提高, 分别提高 $18.4 \%$ 、 $29.5 \%$ 和 $45.1 \%$ ，灌浆期提高幅度最大。

间作中, 小麦间作玉米共生前期玉米密度和地 下互作强度对 $C_{\mathrm{i}}$ 的影响差异显著, 且二者互作显著, 无年际间差异(图 4)。完全地下互作处理较部分地下 线互作和无地下互作处理分别提高 $13.4 \%$ 和 $11.6 \%$, 部分地下互作和无地下互作处理间无显著差异。完
全地下互作处理下, 玉米密度的提高使 $C_{\mathrm{i}}$ 降低 $16.6 \%$ 。因此共生前期完全地下互作处理有利于 $C_{\mathrm{i}}$ 提高, 低玉米密度对其产生促进作用。小麦间作玉 米共生中期, 玉米密度与地下互作强度对小麦 $C_{\mathrm{i}}$ 的 影响差异显著, 且二者存在互作, 年际间差异显著。 3 年数值平均后, 完全地下互作处理较部分地下互 作和无地下互作处理分别提高 $15.6 \%$ 和 $57.5 \%$, 部分 地下互作较无地下互作处理提高 $37.2 \%$ 。完全地下 互作处理下, 高玉米密度较低密度显著提高 $C_{\mathrm{i}}$ $16.0 \%$, 相反, 部分地下互作处理下, 高玉米密度较 低密度显著降低 $20.6 \%$, 无地下互作处理对于玉米 密度的响应年际间差异较大。说明共生中期完全地 下互作处理可显著提高间作小麦 $C_{\mathrm{i}}$, 玉米密度增加 可促进其增加, 而对部分地下互作处理起到相反的 作用。小麦间作玉米共生后期, 玉米密度与地下互 作强度对小麦 $C_{\mathrm{i}}$ 的影响差异显著, 且二者存在互作 效应, 年际间差异显著。完全地下互作处理较部分 地下互作和无地下互作处理 3 年平均值分别提高 $25.1 \%$ 和 $33.3 \%, 2016$ 年和 2017 年, 部分地下互作较 无地下互作处理分别提高 $13.6 \%$ 和 $17.3 \%$ 。完全互作 处理下, 高玉米密度较低密度提高 $C_{\mathrm{i}} 16.9 \%$, 相反,
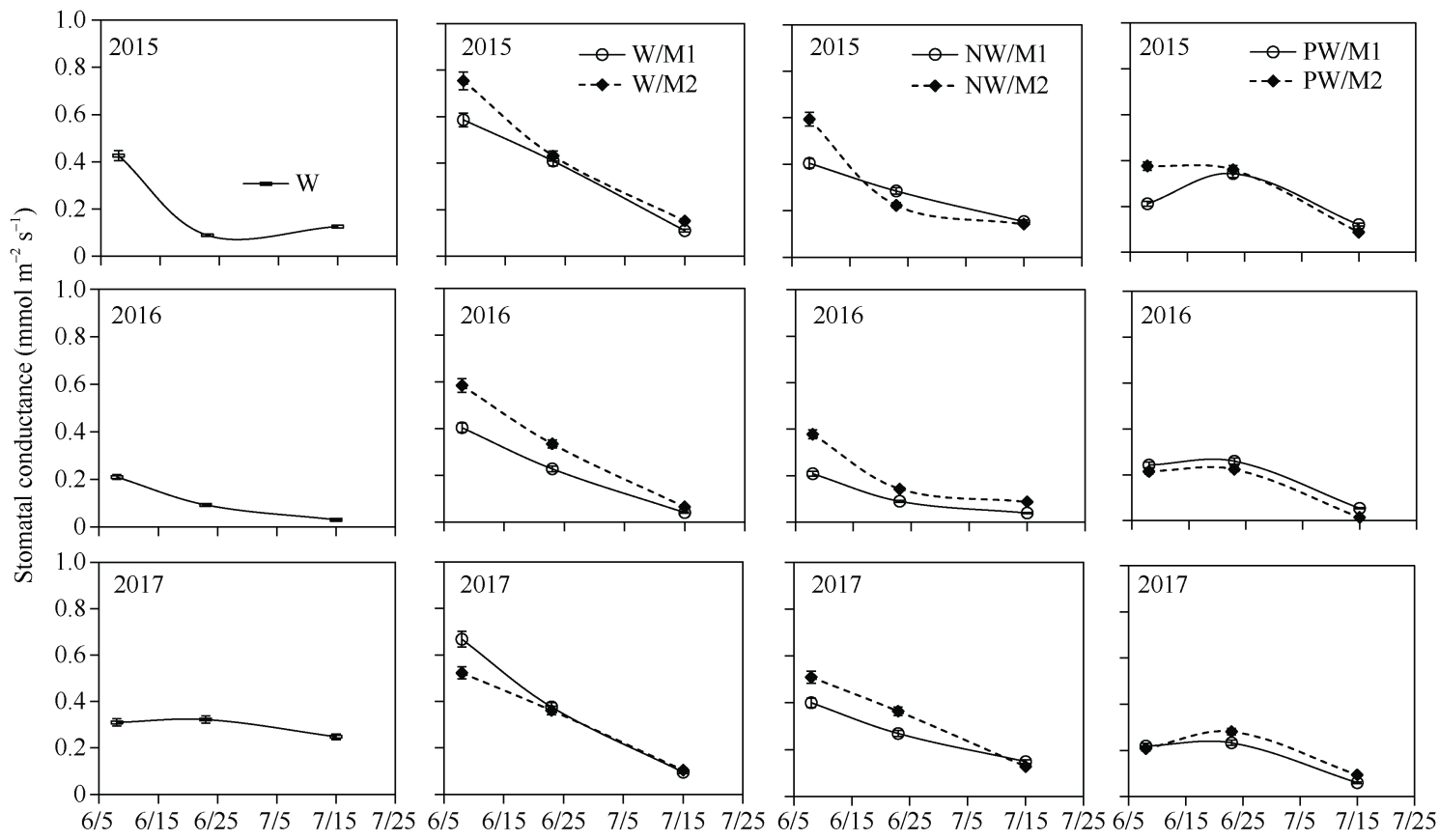

Date (month/day)

图 3 不同地上地下互作强度下间作小麦气孔导度时间动态

Fig. 3 Temporal dynamics of stomatal conductance of intercropped wheat under different above- and below-ground interaction intensities

$\mathrm{W}$ : 单作小麦; M1：低密度单作玉米; M2: 高密度单作玉米; $\mathrm{N}$ : 尼龙网隔根; $\mathrm{P}$ : 塑料布隔根。误差线为标准误差。

W: sole wheat; M1: sole maize in low density; M2: sole maize in high density; N: nylon mesh barrier; P: plastic sheet barrier. The error bar indicates standard error. 


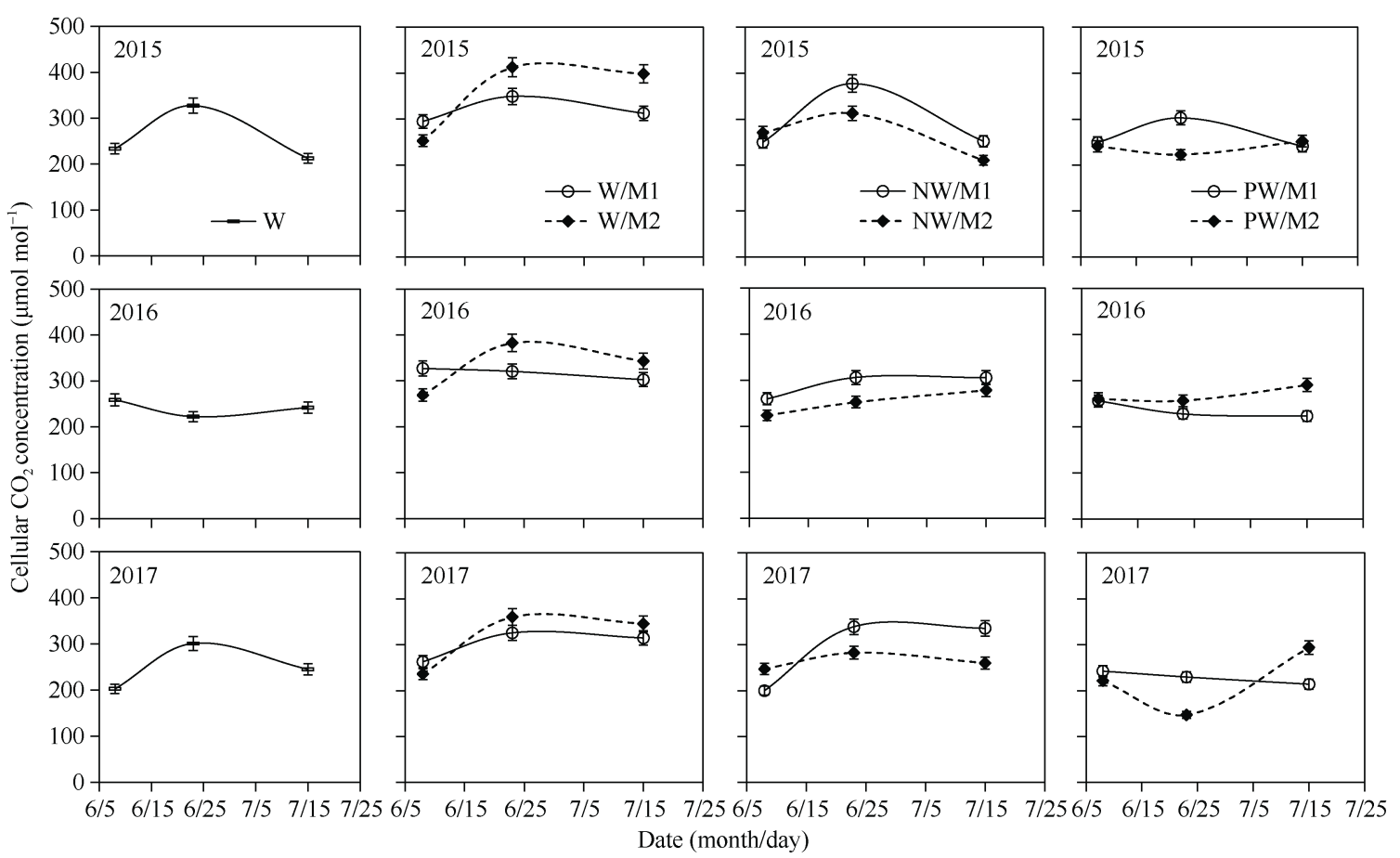

图 4 不同地上地下互作强度下间作小麦胞间 $\mathrm{CO}_{2}$ 浓度的时间动态

Fig. 4 Temporal dynamics of $C_{\mathrm{i}}$ of intercropped wheat under different above- and below-ground interaction intensities $\mathrm{W}$ : 单作小麦; $\mathrm{M} 1$ : 低密度单作玉米; $\mathrm{M} 2$ : 高密度单作玉米; $\mathrm{N}$ : 尼龙网隔根; $\mathrm{P}$ : 塑料布隔根。误差线为标准误差。

W: sole wheat; M1: sole maize in low density; M2: sole maize in high density; N: nylon mesh barrier; P: plastic sheet barrier. The error bar indicates standard error.

部分地下互作处理下，高玉米密度较低密度显著 降低 $19.6 \%$ ，无地下互作处理在 2016 年和 2017 年, 高玉米密度较低密度分别提高 $30.2 \%$ 和 $37.4 \%$ 。说 明共生后期完全地下互作处理可显著提高间作小 麦 $C_{\mathrm{i}}$, 玉米密度的增加促使完全地下互作和无地 下互作处理 $C_{\mathrm{i}}$ 提高, 但降低了部分地下互作处理 的值。

2.1.4 蒸腾速率 $\left(T_{\mathrm{r}}\right)$ 单作较间作抽穗期小麦 $T_{\mathrm{r}}$ 提高 $22.9 \%$, 开花期无显著差异; 灌浆期, $T_{\mathrm{r}}$ 呈降低 趋势，但间作降低的幅度小于单作，间作较单作提 高 12.4\% (图 5)。

间作群体内, 玉米密度对小麦 $T_{\mathrm{r}}$ 无显著影响, 地下互作强度影响显著, 二者互作不显著, 年际间 差异不显著(图 5)。小麦间作玉米共生前期, 地下互 作对 $T_{\mathrm{r}}$ 影响无显著差异; 共生中期, 无地下互作处 理具有较高的 $T_{\mathrm{r}}$, 较完全地下互作处理和部分地下 互作分别增加 $10.6 \%$ 和 $7.1 \%$; 共生后期, 无地下互 作处理仍具有较高的 $T_{\mathrm{r}}$, 较完全地下互作和部分地 下互作分别高 $14.9 \%$ 和 $12.9 \%$; 完全地下互作与部分 地下互作无差异。因此，无地下互作处理在小麦间 作玉米共生中期和后期叶片 $T_{\mathrm{r}}$ 较高, 而完全地下互
作和部分地下互作在这两个时期保持了较低的 $T_{\mathrm{r}}$ 。

\section{2 叶绿素值(SPAD)}

间作可提高小麦花期和灌浆期的 SPAD 值(图 6)。 小麦抽穗期，单作较间作小麦 SPAD 值提高 $21.0 \%$, 开花期和灌浆期, 间作的 SPAD 值显著高于单作, 较单作分别增加 $12.8 \%$ 和 $17.6 \%$ 。间作群体中，小麦 间作玉米共生前期，间作地下互作强度和玉米密度 对小麦 SPAD 值影响差异不显著。共生中期, 地下互 作强度对小麦 SPAD 值的影响差异显著, 玉米密度 对其影响不显著, 二者无互作, 年际间差异不显著。 完全地下互作与部分互作处理间无显著差异, 较无 地下互作处理显著提高小麦 SPAD 值 $8.6 \%$ 。共生后 期, 间作地下互作强度对小麦叶绿素值影响差异显 著, 玉米密度对其影响不显著, 二者无互作, 年际 间差异显著。部分地下互作处理在共生后期的 SPAD 值最高, 较完全地下互作和无地下互作处理 3 年平均提高 $19.3 \%$ 和 $27.0 \%$, 完全地下互作较无 地下互作处理在 2015 年和 2017 年分别高 $18.9 \%$ 和 $16.0 \%$ 。说明完全地下互作有利于提高共生中期的 SPAD 值, 而在共生后期部分地下互作更有利于提 高 SPAD 值。 

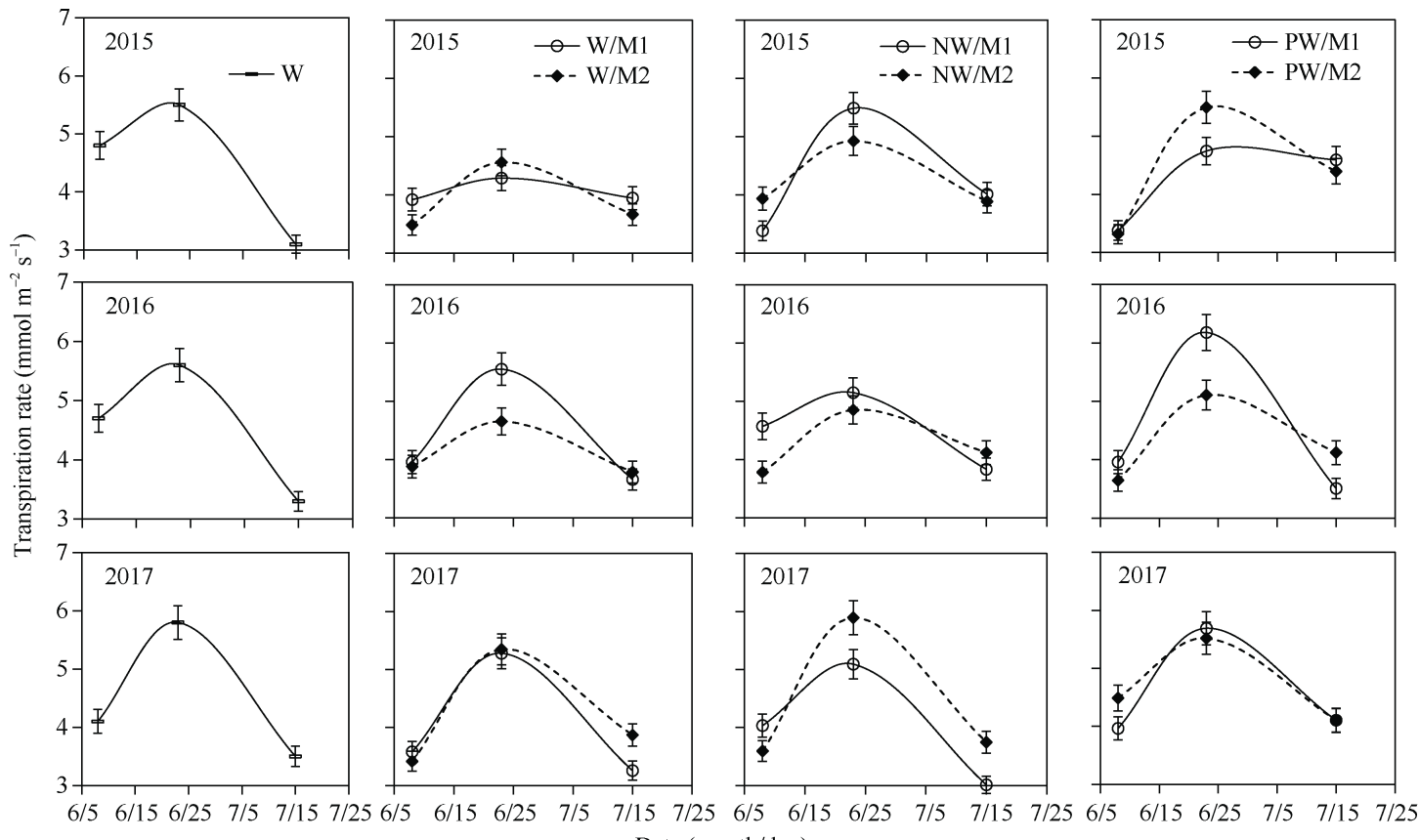

Date (month/day)

图 5 不同地上地下互作强度下间作小麦蒸腾速率的时间动态

Fig. 5 Temporal dynamics of $T_{\mathrm{r}}$ of intercropped wheat under different above- and below-ground interaction intensities $\mathrm{W}$ : 单作小麦; M1: 低密度单作玉米; M2: 高密度单作玉米; $\mathrm{N}$ : 尼龙网隔根; $\mathrm{P}$ : 塑料布隔根。误差线为标准误差。

W: sole wheat; M1: sole maize in low density; M2: sole maize in high density; N: nylon mesh barrier; P: plastic sheet barrier. The error bar indicates standard error.
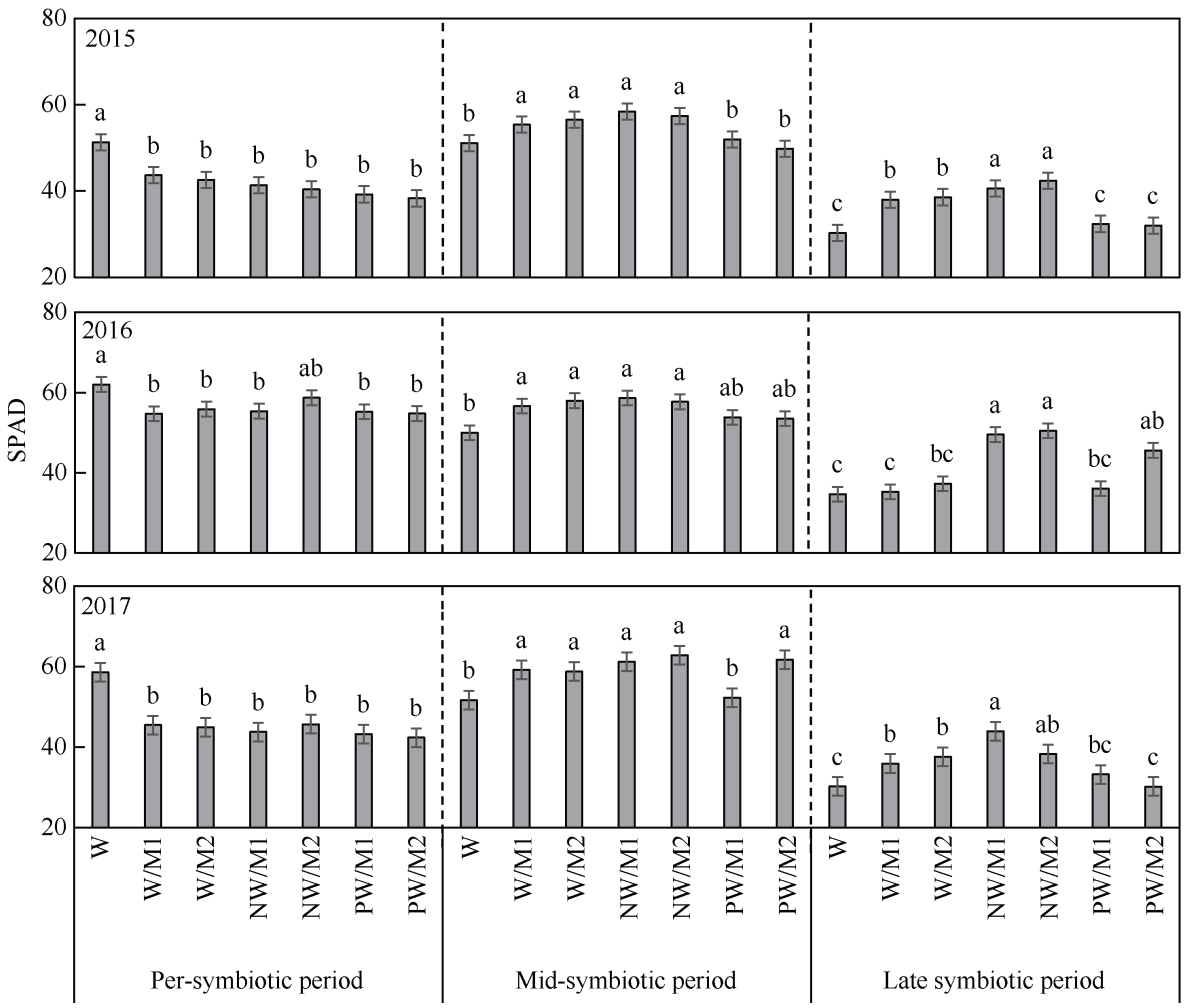

图 6 不同地上地下互作强度下间作小麦相对叶绿素值的时间动态

Fig. 6 Temporal dynamics of SPAD of intercropped wheat under different above- and below-ground interaction intensities $\mathrm{W}$ : 单作小麦; M1: 低密度单作玉米; M2: 高密度单作玉米; $\mathrm{N}$ : 尼龙网隔根; $\mathrm{P}$ : 塑料布隔根。误差线为标准误差。其上所标不同字母 表示处理间差异显著 $(P<0.05)$ 。

W: sole wheat; M1: sole maize in low density; M2: sole maize in high density; N: nylon mesh barrier; P: plastic sheet barrier. The error bar indicates standard error. Different letters above error bars indicate significant differences at $P<0.05$ among treatments. 
2.3 不同地上地下互作强度下间作小麦不同时 期的叶日积的影响

间作较单作具有提高小麦叶日积(LAD)的优势 (表 1)。小麦抽穗期, 间作 LAD 与单作差异不显著, 开花期间作较单作提高小麦 $24.3 \%$ 和 $31.0 \%$ 。间作可 提高小麦生育后期叶日积，使其光合利用率提高。

间作群体内，地下互作强度对小麦 LAD 的影响 差异显著, 玉米密度对其影响差异不显著, 二者无 互作(表 1)。小麦间作玉米共生前期、中期以及后期, 完全地下互作较部分地下互作处理小麦 LAD 分别
提高 $10.4 \%$ 、 $12.6 \%$ 和 $11.5 \%$, 较无地下互作处理的 分别提高 $22.7 \%$ 、 $29.3 \%$ 和 $34.2 \%$, 部分地下互作较 无地下互作处理分别提高 $11.2 \% 、 14.8 \%$ 和 $20.3 \%$ 。 随生育期的推进, 完全地下互作处理下间作小麦 $\mathrm{LAD}$ 提高比率随之增加。

2.4 间作小麦籽粒产量、收获指数以及与光合参 数的相关性

间作系统中，各处理土地当量比(LER)均大于 1 (表 2), 说明间作处理较单作具有显著的增产效应。 完全地下互作、部分地下互作和无地下互作处理中

表 1 不同地上地下互作强度下间作小麦不同时期的叶日积

Table 1 Leaf daily accumulation of intercropping wheat at different stages under different above- and below-ground interaction intensities

\begin{tabular}{|c|c|c|c|c|}
\hline $\begin{array}{l}\text { 年份 } \\
\text { Year }\end{array}$ & $\begin{array}{c}\text { 处理 } \\
\text { Treatment }\end{array}$ & $\begin{array}{c}\text { 小麦间作玉米共生前期 } \\
\text { Per-symbiotic period }\end{array}$ & $\begin{array}{c}\text { 小麦间作玉米共生中期 } \\
\text { Mid-symbiotic period }\end{array}$ & $\begin{array}{c}\text { 小麦间作玉米共生后期 } \\
\text { Late symbiotic period }\end{array}$ \\
\hline \multirow[t]{7}{*}{2015} & $\mathrm{~W}$ & $71.3 \mathrm{ab}$ & $84.9 \mathrm{c}$ & $55.7 \mathrm{~cd}$ \\
\hline & W/M1 & $75.4 \mathrm{a}$ & $119.2 \mathrm{a}$ & $76.3 \mathrm{a}$ \\
\hline & W/M2 & $78.6 \mathrm{a}$ & $109.7 \mathrm{a}$ & $74.3 \mathrm{a}$ \\
\hline & NW/M1 & $69.2 \mathrm{~b}$ & $102.3 \mathrm{~b}$ & $68.9 \mathrm{~b}$ \\
\hline & $\mathrm{NW} / \mathrm{M} 2$ & $70.0 \mathrm{~b}$ & $97.4 \mathrm{~b}$ & $69.1 \mathrm{~b}$ \\
\hline & PW/M1 & $61.8 \mathrm{c}$ & $88.2 \mathrm{c}$ & $58.3 \mathrm{c}$ \\
\hline & PW/M2 & $65.0 \mathrm{bc}$ & $81.9 \mathrm{c}$ & $52.9 \mathrm{~d}$ \\
\hline \multirow[t]{7}{*}{2016} & $\mathrm{~W}$ & $68.9 \mathrm{~b}$ & $87.8 \mathrm{~cd}$ & $55.3 \mathrm{~d}$ \\
\hline & $\mathrm{W} / \mathrm{M} 1$ & $76.0 \mathrm{a}$ & $109.7 \mathrm{a}$ & $77.8 \mathrm{a}$ \\
\hline & W/M2 & $76.4 \mathrm{a}$ & $105.3 \mathrm{ab}$ & $70.4 \mathrm{~b}$ \\
\hline & NW/M1 & $71.2 \mathrm{~b}$ & $100.4 \mathrm{~b}$ & $66.3 \mathrm{c}$ \\
\hline & NW/M2 & $71.4 \mathrm{~b}$ & $97.4 \mathrm{~b}$ & $65.2 \mathrm{c}$ \\
\hline & PW/M1 & $62.8 \mathrm{c}$ & $89.4 \mathrm{c}$ & $55.8 \mathrm{~d}$ \\
\hline & $\mathrm{PW} / \mathrm{M} 2$ & $64.1 \mathrm{c}$ & $83.6 \mathrm{~d}$ & $57.9 \mathrm{~d}$ \\
\hline \multirow[t]{7}{*}{2017} & W & $72.8 \mathrm{~b}$ & $88.3 \mathrm{~b}$ & $57.6 \mathrm{c}$ \\
\hline & W/M1 & $77.0 \mathrm{a}$ & $105.4 \mathrm{a}$ & $70.4 \mathrm{a}$ \\
\hline & W/M2 & $76.8 \mathrm{a}$ & $98.7 \mathrm{a}$ & $72.3 \mathrm{a}$ \\
\hline & NW/M1 & $65.4 \mathrm{c}$ & $89.3 \mathrm{~b}$ & $66.1 \mathrm{~b}$ \\
\hline & $\mathrm{NW} / \mathrm{M} 2$ & $70.1 \mathrm{~b}$ & $88.8 \mathrm{~b}$ & $60.4 \mathrm{~b}$ \\
\hline & PW/M1 & $59.8 \mathrm{~d}$ & $80.2 \mathrm{bc}$ & $53.9 \mathrm{~d}$ \\
\hline & $\mathrm{PW} / \mathrm{M} 2$ & $61.8 \mathrm{c}$ & $77.9 \mathrm{c}$ & $50.4 \mathrm{~d}$ \\
\hline \multicolumn{5}{|c|}{ 显著性 Significant } \\
\hline \multicolumn{2}{|c|}{ 年际 Year (Y) } & NS & NS & NS \\
\hline \multicolumn{2}{|c|}{ 种植模式 Planting pattern (P) } & $* *$ & $* *$ & $* *$ \\
\hline \multicolumn{2}{|c|}{ 地下互作强度 Below-ground interaction (I) } & $* *$ & $* *$ & $* *$ \\
\hline \multicolumn{2}{|c|}{ 密度 Density (D) } & NS & NS & NS \\
\hline \multicolumn{2}{|l|}{$\mathrm{I} \times \mathrm{D}$} & NS & NS & NS \\
\hline
\end{tabular}

数据后不同字母表示同一年度中处理间差异显著 $(P<0.05)$ 。NS、*和**分别表示无显著差异及在 0.05 和 0.01 水平上差异显著。W: 单 作小麦; M1：低密度单作玉米; M2：高密度单作玉米; N：尼龙网隔根; P: 塑料布隔根。

In each year, different letters followed by values indicate significant differences at $P<0.05$ among treatments. NS, *, ** indicate non-significant or significant at $P<0.05$ or $P<0.01$, respectively. W: sole wheat; M1: sole maize in low density; M2: sole maize in high density; N: nylon mesh barrier; P: plastic sheet barrier. 
小麦籽粒产量分别达到了相应单作产量的 $76.8 \%$ 、 $66.8 \%$ 和 $61.0 \%$ 。

间作群体内，地下互作强度对小麦籽粒产量影 响差异显著, 玉米密度影响不显著, 二者无互作, 年际间差异不显著(表 2)。从 3 年试验的平均来看, 完全地下互作较部分地下互作和无地下互作处理小 麦籽粒产量分别增加 $11.2 \%$ 和 $25.0 \%$ ，部分地下互作 较无地下互作增加 $12.3 \%$ 。地下互作强度和玉米密 度对总籽粒产量的影响差异显著, 二者互作显著, 年际间差异不显著。地上地下部完全互作对籽粒产 量的贡献率为 $23.7 \%$, 密度增加使其增加 $7.3 \%$, 部 分地下互作对籽粒产量的贡献率为 $13.7 \%$ ，密度增 加使其增加 $3.7 \%$, 仅地上部分互作对籽粒产量的贡 献率为 $9.0 \%$, 密度增加使其增加 $3.5 \%$ 。地下互作强 度和玉米密度对 LER 的影响差异显著, 二者存在互 作效应，年际间差异不显著。从 3 年平均来看，完全 地下互作处理较部分地下互作和无地下互作处理分 别提高 $9.1 \%$ 和 $26.2 \%$ 。因此，间作体系中完全地下 互作提高了间作群体籽粒产量和组分小麦籽粒产量, 且对群体籽粒产量而言密植促使完全地下互作发挥 正效应。
小麦收获指数存在年际间差异, 2015 年差异不 显著, 在 2016 年和 2017 年间作小麦收获指数较单 作分别提高 $27.0 \%$ 和 $17.4 \%$ (图 7)。间作群体内, 地 下互作强度对小麦收获指数的影响差异显著, 玉米 密度对其影响不显著，二者无互作，年际间差异显 著。2015 年和 2017 年, 完全地下互作较无地下互作 处理小麦收获指数分别提高 $12.3 \%$ 和 $13.8 \%$ ，部分地 下互作与无地下互作处理间差异不显著。完全地下 互作处理对小麦收获指数的提高具有显著的促进作 用, 部分地下互作和无地下互作均无显著影响。

\section{$2.5 P_{\mathrm{n}} 、 G_{\mathrm{s}} 、 C_{\mathrm{i}} 、 T_{\mathrm{r}} 、 \mathrm{SPAD}$ 以及 $\mathrm{LAD}$ 与群体总} 产量和小麦产量的相关性

小麦间作玉米共生前期，总产量与小麦 $G_{\mathrm{s}}$ 呈显 著正相关关系，小麦籽粒产量与 $T_{\mathrm{r}} 、 \mathrm{LAD}$ 呈显著正 相关关系，与 SPAD 值呈极显著正相关关系(表 3)。 小麦间作玉米共生中期, 总产量与小麦 $C_{\mathrm{i}} 、 \mathrm{LAD}$ 呈 显著正相关关系，与 SPAD 值呈极显著相关关系。小 麦间作玉米共生后期, 总产量与小麦 $P_{\mathrm{n}} 、 C_{\mathrm{i}} 、 \mathrm{SPAD}$ 值以及 $\mathrm{LAD}$ 均呈正相关关系, 其中, 与 $C_{\mathrm{i}}$ 和 $\mathrm{LAD}$ 呈极显著正相关关系，相反，小麦籽粒产量与 $T_{\mathrm{r}}$ 呈 极显著负相关关系。

表 2 不同地上地下互作强度下间作小麦籽粒产量及群体籽粒产量

Table 2 Grain yield and population grain yield of intercropping wheat under different above- and below-ground interaction intensity

\begin{tabular}{|c|c|c|c|c|c|c|c|c|c|}
\hline \multirow{2}{*}{$\begin{array}{c}\text { 处理 } \\
\text { Treatment }\end{array}$} & \multicolumn{3}{|c|}{2015} & \multicolumn{3}{|c|}{2016} & \multicolumn{3}{|c|}{2017} \\
\hline & $\begin{array}{c}\text { 小麦 } \\
\text { Wheat }\end{array}$ & $\begin{array}{l}\text { 总和 } \\
\text { Total }\end{array}$ & $\begin{array}{l}\text { 土地当量 } \\
\text { 比 LER }\end{array}$ & $\begin{array}{c}\text { 小麦 } \\
\text { Wheat }\end{array}$ & $\begin{array}{l}\text { 总和 } \\
\text { Total }\end{array}$ & $\begin{array}{l}\text { 土地当量 } \\
\text { 比 LER }\end{array}$ & $\begin{array}{c}\text { 小麦 } \\
\text { Wheat }\end{array}$ & $\begin{array}{l}\text { 总和 } \\
\text { Total }\end{array}$ & $\begin{array}{l}\text { 土地当量 } \\
\text { 比 LER }\end{array}$ \\
\hline W & $6070 \mathrm{a}$ & $6070 \mathrm{f}$ & & 6313 a & $6313 \mathrm{f}$ & & $6182 \mathrm{a}$ & $6182 \mathrm{e}$ & \\
\hline W/M1 & $4434 \mathrm{~b}$ & $13,584 \mathrm{~b}$ & $1.44 \mathrm{~b}$ & $5327 \mathrm{~b}$ & $15,781 \mathrm{bc}$ & $1.68 \mathrm{a}$ & $4697 \mathrm{c}$ & $15,279 \mathrm{~b}$ & $1.59 \mathrm{a}$ \\
\hline W/M2 & $4514 \mathrm{~b}$ & $15,322 \mathrm{a}$ & $1.53 \mathrm{a}$ & $5400 \mathrm{~b}$ & $17,203 \mathrm{a}$ & $1.63 \mathrm{a}$ & $4942 \mathrm{~b}$ & $16,641 \mathrm{a}$ & $1.59 \mathrm{a}$ \\
\hline NW/M1 & $4002 \mathrm{c}$ & $12,761 \mathrm{c}$ & $1.34 \mathrm{c}$ & $5026 \mathrm{c}$ & $14,926 \mathrm{~d}$ & $1.60 \mathrm{a}$ & $4422 \mathrm{~d}$ & $13,326 \mathrm{de}$ & $1.41 \mathrm{~b}$ \\
\hline NW/M2 & $3917 \mathrm{c}$ & $13,769 \mathrm{~b}$ & $1.36 \mathrm{~b}$ & $4876 \mathrm{~cd}$ & $16,271 \mathrm{~b}$ & $1.52 \mathrm{~b}$ & $4153 \mathrm{e}$ & $13,959 \mathrm{~d}$ & $1.34 \mathrm{~b}$ \\
\hline PW/M1 & $3451 \mathrm{~d}$ & $11,600 \mathrm{e}$ & $1.20 \mathrm{~d}$ & $4718 \mathrm{~d}$ & $12,722 \mathrm{e}$ & $1.40 \mathrm{c}$ & $3700 \mathrm{f}$ & $11,859 \mathrm{f}$ & $1.15 \mathrm{c}$ \\
\hline $\mathrm{PW} / \mathrm{M} 2$ & $3609 \mathrm{~d}$ & $12,045 \mathrm{~d}$ & $1.21 \mathrm{~d}$ & $4475 \mathrm{e}$ & $13,626 \mathrm{c}$ & $1.30 \mathrm{~d}$ & $3626 \mathrm{f}$ & $11,860 \mathrm{f}$ & $1.24 \mathrm{c}$ \\
\hline 显著性 Significant & & & & & & & & & \\
\hline 年际 Year (Y) & NS & NS & NS & - & - & - & - & - & - \\
\hline 种植模式 Planting pattern (P) & $* *$ & $* *$ & - & $* *$ & $* *$ & - & $* *$ & $* *$ & - \\
\hline 密度 Density (D) & NS & ** & $* *$ & $* *$ & $* *$ & $* *$ & $*$ & $* *$ & NS \\
\hline $\begin{array}{l}\text { 地下作用强度 } \\
\text { Below-ground interaction (I) }\end{array}$ & $* *$ & $* *$ & $* *$ & $*$ & ** & $* *$ & $* *$ & $* *$ & $* *$ \\
\hline$I \times D$ & NS & $* *$ & $* *$ & NS & NS & $* *$ & $*$ & NS & $* *$ \\
\hline
\end{tabular}

数据后不同字母表示同一年度中处理间差异显著 $(P<0.05)$ 。NS、*和**分别表示无显著差异及在 0.05 和 0.01 水平上差异显著。W: 单 作小麦; M1：低密度单作玉米; M2：高密度单作玉米; N：尼龙网隔根; P: 塑料布隔根。

In each year, different letters followed by values indicate significant differences at $P<0.05$ among treatments. W: sole wheat; M1: sole maize in low density; M2: sole maize in high density; N: nylon mesh barrier; P: plastic sheet barrier; LER: land equivalent ratio. NS, ${ }^{*}, *$ indicate non-significant or significant at $P<0.05$ or $P<0.01$, respectively. 


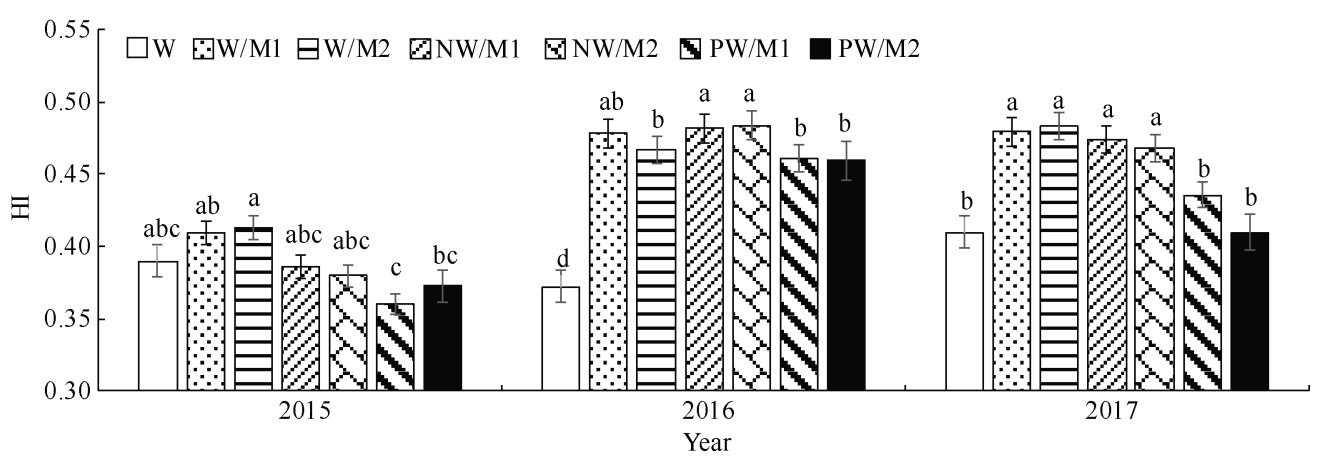

图 7 不同地上地下互作强度下间作小麦收获指数

Fig. 7 Harvest index (HI) of intercropped wheat under different above- and below-ground interaction intensities

$\mathrm{W}$ : 单作小麦; $\mathrm{M} 1$ : 低密度单作玉米; M2: 高密度单作玉米; $\mathrm{N}$ : 尼龙网隔根; $\mathrm{P}$ : 塑料布隔根。误差线为标准误差。其上所标不同字母 表示处理间差异显著 $(P<0.05)$ 。

W: sole wheat; M1: sole maize in low density; M2: sole maize in high density; N: nylon mesh barrier; P: plastic sheet barrier. The error bar indicates standard error. Different letters above error bars indicate significant differences at $P<0.05$ among treatments.

表 3 籽粒产量与净光合速率、气孔导度、胞间 $\mathrm{CO}_{2}$ 浓度、蒸腾速率、相对叶绿素值、叶日积的相关关系

Table 3 Correlation of grain yield with $P_{\mathrm{n}}, G_{\mathrm{s}}, C_{\mathrm{i}}, T_{\mathrm{r}}$, SPAD, and LAD

\begin{tabular}{clccc}
\hline $\begin{array}{c}\text { 项目 } \\
\text { Item }\end{array}$ & $\begin{array}{c}\text { 指标 } \\
\text { Index }\end{array}$ & $\begin{array}{c}\text { 小麦间作玉米共生前期 } \\
\text { Pre-symbiotic period }\end{array}$ & $\begin{array}{c}\text { 小麦间作玉米共生中期 } \\
\text { Mid-symbiotic period }\end{array}$ & $\begin{array}{c}\text { 小麦间作玉米共生后期 } \\
\text { Late symbiotic period }\end{array}$ \\
\hline 总产量 & $P_{\mathrm{n}}$ & 0.18 & -0.26 & 0.13 \\
Total yield & $G_{\mathrm{s}}$ & $0.53^{*}$ & 0.20 & -0.27 \\
& $C_{\mathrm{i}}$ & 0.34 & $0.45^{*}$ & $0.57^{* *}$ \\
& $T_{\mathrm{r}}$ & -0.39 & -0.43 & 0.11 \\
& SPAD & -0.17 & $0.59^{* *}$ & $0.50^{*}$ \\
小麦产量 & LAD & 0.42 & $0.52^{*}$ & $0.64^{* *}$ \\
Wheat yield & $P_{\mathrm{n}}$ & 0.11 & -0.23 & $0.51^{*}$ \\
& $G_{\mathrm{s}}$ & 0.00 & -0.32 & -0.05 \\
& $C_{\mathrm{i}}$ & 0.09 & 0.17 & 0.19 \\
& $T_{\mathrm{r}}$ & $0.46^{*}$ & 0.13 & $-0.61^{* *}$ \\
& SPAD & $0.85^{* *}$ & -0.17 & 0.06 \\
& LAD & $0.52^{*}$ & 0.27 & 0.21 \\
\hline
\end{tabular}

"和**分别表示在 $P<0.05$ 和 $P<0.01$ 水平下显著相关。

${ }^{*}$ and ${ }^{* *}$ indicate significant correlations at $P<0.05$ and $P<0.01$, respectively.

\section{3 讨论}

\section{1 地上地下互作强度对间作小麦光合生理的 影响}

间作种植模式可在时间和空间上集约利用光、 热、水、肥、气等资源, 改善群体内的通风条件, 促 使不同生态位的作物和谐共生 ${ }^{[14-15]}$ 。间作地下部根 系分隔在不同程度上降低了作物对养分和水分的吸 收利用, 研究表明玉米间作大豆系统中, 尼龙网和 塑料布隔根较不隔根均使大豆氮肥利用效率下降, 从而使产量降低 ${ }^{[16]}$, 玉米间作踠豆体系中, 尼龙网 和塑料布隔根下系统水分利用效率较不隔根显著降 低 ${ }^{[17]}$, 因此, 要充分发挥间作增产优势, 间作地下
部完全互作是必要前提。光合作用是作物产量形成 的基础, 间作群体内高矮作物相间种植形成了良好 的冠层结构, 高位作物可充分利用光能提高 $P_{\mathrm{n}} 、 G_{\mathrm{s}}$ 、 $C_{\mathrm{i}}$ 和 $T_{\mathrm{r}}{ }^{[18]}$, 但对低位作物来说, 在某些生长阶段受 高位作物荫蔽影响处于弱光胁迫环境中, 导致其生 长发育受限, 作物产量提升也受到约束 ${ }^{[13]}$ 。研究表 明, 通过优化作物组合的行比、行株距、播种密度 和施肥等, 可适当减少弱光胁迫, 改善低位作物的 光合特性 ${ }^{[19]}$ 。本研究中, 小麦灌浆期是小麦间作玉 米共生后期, 小麦处于玉米遮阴程度最大阶段, 这 一时期完全地下互作处理促使小麦 $P_{\mathrm{n}}$ 较无地下互作 处理提高 $32.0 \%$, 且玉米密度的增加促使完全地下 互作效应增强, 进一步提高 $P_{\mathrm{n}} \quad 10.7 \%$, 这可能是由 
于小麦间作玉米系统小麦叶绿素含量增加 ${ }^{[20]}$, 使其 绿叶时期延长, 致使小麦间作玉米共生后期小麦光 合速率显著提高。从与籽粒产量的相关性来看, 小 麦间作玉米共生后期小麦 $P_{\mathrm{n}}$ 与小麦籽粒产量呈显著 正相关关系, 说明通过增加玉米密度提高完全地下 互作处理的互作强度是提高小麦 $P_{\mathrm{n}}$ 的途径之一。

气孔作为植物与外界环境进行水气交换的通道, 气孔影响着叶片蒸腾、光合等生理过程, 研究表明 气孔导度与蒸腾速率的显著提高对糜子叶片水分蒸 腾散失和 $\mathrm{CO}_{2}$ 同化具有调控作用 ${ }^{[21]}$, 使间作糜子增 加对强光的适应能力。本研究中, 小麦间作玉米共 生前期、中期和后期，完全地下互作处理可显著提 高小麦 $G_{\mathrm{s}}$ 和 $C_{\mathrm{i}}$, 而且玉米密度提高对共生前期完全 地下互作处理和部分地下互作处理小麦 $G_{\mathrm{s}}$ 的增加起 到促进作用。这可能是由于小麦玉米共生前期, 玉 米生长对小麦起到较低程度的遮阴, 有利于群体温 度的降低, 气孔开放 ${ }^{[22]}$ 。另有研究表明间作模式下, 低位作物的蒸腾速率均有所降低 ${ }^{[23-24]}$, 本研究中无 地下互作处理在共生中期和后期叶片 $T_{\mathrm{r}}$ 较高, 而 完全地下互作和部分地下互作在这两个时期保持了 较低的 $T_{\mathrm{r}}$, 结合净光合速率的比较结果来看, 说明 完全地下互作处理和部分地下互作处理在共生中期 和后期均有较高的叶片水分利用效率。

\section{2 地上地下互作强度对间作小麦 LAD 和 SPAD 的影响}

作物处在弱光环境时叶源的变化主要表现为单 株叶面积或群体叶面积指数的降低 ${ }^{[25]}$, 有研究表明 弱光处理后作物叶面积指数显著降低, 导致其干物 质积累降低, 是作物减产的主要因素之一 ${ }^{[26-27]}$ 。但 弱光处理后作物会通过提高叶片中的叶绿素 $a$ 、叶 绿素 $b$ 和总叶绿素含量及降低叶绿素 $a / b$ 比值来增 强叶片的光能捕获能力, 对光合有效辐射截获量的 降低起到一定的补偿作用 ${ }^{[9]}$ 。本研究中, 小麦间作玉 米共生中期, 完全地下互作处理使叶片 SPAD 值较 无地下互作处理显著增加 $8.6 \%$, 此时有利于光合强 度的提高。间作完全地下互作处理有助于小麦 LAD 的增加, 且小麦间作玉米共生后期提高比率最大, 也就是说随着玉米遮阴程度的增加小麦 LAD 随之 增加。从与籽粒产量的相关性来看, 在小麦间作玉 米共生中期通过提高间作小麦 SPAD 值和共生后期 LAD 是提高间作总产量的重要途径。

3.3 地上地下互作强度对间作籽粒产量的影响 间作作物地上、地下部的互作是间作群体高产、
高效的主要原因之一 ${ }^{[28-29]}$, 本研究中, 间作小麦具 有显著的增产效应, 完全地下互作处理中小麦籽粒 产量达到相应单作产量的 $76.8 \%$, 具有显著提高间 作群体籽粒产量的优势, 且地上部互作强度增强有 利于完全地下互作处理正效应的发挥。收获指数代 表植物光合作用产物转化为籽粒产量的比率, 间作 小麦的收获指数高于单作, 表明在间作模式中小麦 由营养生殖向生殖生长的干物质积累转化能力强于 单作小麦。完全地下互作处理具有显著提高小麦收 获指数的作用, 部分地下互作处理和无地下互作处 理对小麦收获指数的提高无显著影响, 主要是由于 完全地下互作处理有利于小麦叶绿素含量增加, 提 高了功能叶片净光合速率, 光合产物的合成和积累 增加, 促使籽粒灌浆和光合物质向籽粒运输分配。

\section{4 结论}

完全地下互作处理显著提高了小麦间作玉米共 生前期和后期的小麦 $P_{\mathrm{n}} 、 G_{\mathrm{s}}$ 和 $C_{\mathrm{i}}$, 且地上互作强度 的增强可促使地下完全互作处理进一步提高共生后 期小麦 $P_{\mathrm{n}}$; 在小麦间作玉米共生中期和后期, 完全 地下互作处理可保持较低水平的 $T_{\mathrm{r}}$ 。随着生育进程 的推进, 完全地下互作处理促使间作小麦 LAD 提高 比率越大。另外, 小麦间作玉米共生中期, 完全地下 互作处理下叶片 SPAD 值显著提高, 光合强度增强。 完全地下互作处理可显著提高间作小麦籽粒产量和 收获指数, 且地上互作强度增强对完全地下互作小 麦籽粒产量的提高起到促进作用, 在生产实践中可 通过调节地上地下互作强度的强弱来优化低位作物 光合性能提高其产量。

\section{References}

[1] Yin W, Chai Q, Guo Y, Feng F X, Zhao C, Yu A Z, Hu F L. Analysis of leaf area index dynamic and grain yield components of intercropped wheat and maize under straw mulch combined with reduced tillage in arid environments. $J$ Agric Sci, 2016, 8: 26.

[2] Hu F L, Gan Y T, Chai Q, Feng F X, Zhao C, Yu A Z, Mu Y P, Zhang Y. Boosting system productivity through the improved coordination of interspecific competition in maize/pea strip intercropping. Field Crops Res, 2016, 198: 50-60.

[3] Watiki J M, Fukai S, Banda J A, Keating B A. Radiation interception and growth of maize/cowpea intercrop as affected by maize plant density and cowpea cultivar. Field Crops Res, 1993, 35: 123-133.

[4] 龚万灼, 吴雨珊, 雍太文, 刘卫国, 杨峰, 杨文钰. 玉米-大豆 带状套作中荫蔽及光照恢复对大豆生长特性与产量的影响. 中国油料作物学报, 2015, 37: 475-480. 
Gong W Z, Wu Y S, Yong T W, Liu W G, Yang F, Yang W Y. Effects of shade and lighting recovery on growth and yield of soybean in maize-soybean relay strip intercropping. Chin J Oil Crop Sci, 2015, 37: 475-480 (in Chinese with English abstract).

[5] 高阳, 段爱旺, 刘祖贵, 申孝军. 玉米和大豆条带间作模式下 的光环境特性. 应用生态学报, 2008, 19: 1248-1254.

Gao Y, Duan A W, Liu Z G, Shen X J. Light environment characteristics in maize-soybean strip intercropping system. Chin J Appl Ecol, 2008, 19: 1248-1254 (in Chinese with English abstract).

[6] 杜进勇, 柴强, 王一帆, 范虹, 胡发龙, 殷文, 李登业. 地上地 下互作强度对小麦间作玉米光合特性的影响. 作物学报, 2019, 45: 1398-1406.

Du J Y, Chai Q, Wang Y F, Fan H, Hu F L, Yin W, Li D Y. Effect of above-and below-ground interaction intensity on photosynthetic characteristics of wheat-maize intercropping. Acta Agron Sin, 2019, 45: 1398-1406 (in Chinese with English abstract).

[7] 王一帆, 秦亚洲, 冯福学, 赵财, 于爱忠, 刘畅, 柴强. 根间作 用与密度协同作用对小麦间作玉米产量及产量构成的影响. 作物学报, 2017, 43: 754-762.

Wang Y F, Qin Y Z, Feng F X, Zhao C, Yu A Z, Liu C, Chai Q. Synergistic effect of root interaction and density on yield and yield components of wheat/maize intercropping system. Acta Agron Sin, 2017, 43: 754-762 (in Chinese with English abstract).

[8] Yang C H, Chai Q, Huang G B. Root distribution and yield responses of wheat/maize intercropping to alternate irrigation in the arid areas of northwest China. Plant Soil Environ, 2010, 56: 253-262.

[9] Li H W, Jiang D, Wollenweber B, Dai T B, Cao W X. Effects of shading on morphology, physiology and grain yield of winter wheat. Eur J Agron, 2010, 33: 267-275.

[10] 冯晓敏, 杨永, 任长忠, 胡跃高, 曾昭海. 豆科-燕麦间作对作 物光合特性及籽粒产量的影响. 作物学报, 2015, 41: 1426-1434.

Feng X M, Yang Y, Ren C Z, Hu Y G, Zeng Z H. Effects of legumes intercropping with oat on photosynthesis characteristics of and grain yield. Acta Agron Sin, 2015, 41: 1426-1434 (in Chinese with English abstract).

[11] 焦念元, 李亚辉, 刘领, 齐付国, 尹飞, 宁堂远, 李增嘉, 付占 国. 隔根对玉米/花生间作光合特性与间作优势的影响. 植物 生理学报, 2016, 52: 886-894.

Jiao N Y, Li Y H, Liu L, Qi F G, Yin F, Ning T Y, Li Z J, Fu Z G. Effects of root barrier on photosynthetic characteristics and intercropping advantage of maize/peanut intercropping. Plant Physiol $J$, 2016, 52: 886-894 (in Chinese with English abstract).

[12] 陈光荣, 杨文钰, 张国宏, 王立明, 杨如萍, 雍太文, 刘卫国. 马铃薯/大豆套作对 3 个大豆品种光合指标和产量的影响. 应 用生态学报, 2015, 26: 3345-3352.

Chen G R, Yang W Y, Zhang G H, Wang L M, Yang R P, Yong T W, Liu W G. Effects of potato/soybean intercropping on photosynthetic characteristics and yield of three soybean varieties. Chin J Appl Ecol, 2015, 26: 3345-3352 (in Chinese with English abstract).

[13] 崔亮, 苏本营, 杨峰, 杨文钰. 不同玉米-大豆带状套作组合条 件下光合有效辐射强度分布特征对大豆光合特性和产量的影 响. 中国农业科学, 2014, 47: 1489-1501.

Cui L, Su B Y, Yang F, Yang W Y. Effects of photo-synthetically active radiation on photosynthetic characteristics and yield of soybean in different maize/soybean relay strip intercropping systems. Sci Agric Sin, 2014, 47: 1489-1501 (in Chinese with English abstract).

[14] Yin W, Feng F X, Zhao C, Yu A Z, Hu F L, Chai Q, Gan Y T, Guo Y. Integrated double mulching practices optimizes soil temperature and improves soil water utilization in arid environments. Int J Biometeorol, 2016, 60: 1423-1437.

[15] Chai Q, Qin A Z, Gan Y T, Yu A Z. Higher yield and lower carbon emission by intercropping maize with rape, pea, and wheat in arid irrigation areas. Agron Sustain Dev, 2014, 34: 535-543.

[16] 陈国栋, 柴强. 根系分隔和供水水平对玉米间作㛺豆产量和 耗水特征的影响. 西北农业学报, 2013, 22(12): 25-30.

Chen G D, Chai Q. Effect of root separation and irrigation on yield sand water use characteristics of maize pea intercropping system. Acta Agric Boreali-Occident Sin, 2013, 22(12): 25-30 (in Chinese with English abstract).

[17] 张向前, 黄国勤, 市新民, 赵其国. 施氮肥与隔根对间作大豆 农艺性状和根际微生物数量及酶活性的影响. 土壤学报, 2012, 49: 731-739.

Zhang X Q, Huang G Q, Bian X M, Zhao Q G. Effects of nitrogen ferritization and root separation on agronomic traits of intercropping soybean, quantity of microorganisms and activity of enzymes in soybean rhizosphere. Acta Ped Sin, 2012, 49: 731-739 (in Chinese with English abstract).

[18] Wang Z K, Zhao X N, Wu P T, Gao Y, Yang Q, Shen Y Y. Border row effects on light interception in wheat/maize strip intercropping systems. Field Crops Res, 2017, 214: 1-13.

[19] 王竹, 杨文钰, 吴其林. 玉/豆套作荫蔽对大豆光合特性与产 量的影响. 作物学报, 2007, 33: 1502-1507.

Wang Z, Yang W Y, Wu Q L. Effects of shading in maize/soybean relay-cropping system on the photosynthetic characteristics and yield of soybean. Acta Agron Sin, 2007, 33: 1502-1507 (in Chinese with English abstract).

[20] 杨彩红, 柴强. 交替灌溉对小麦/虫豆间作系统作物生理生态 特性的影响. 中国生态农业学报, 2016, 24: 883-892.

Yang C H, Chai Q. Water use characteristics of alternately irrigated wheat/maize intercropping in oasis region of northwestern china. Chin J Eco-Agric, 2016, 24: 883-892 (in Chinese with English abstract).

[21] 宫香伟, 党科, 李境, 罗艳, 赵冠, 杨璞, 高小丽, 高金锋, 王 鹏科, 冯佰利. 糜子绿豆间作模式下糜子光合物质生产及水 分利用效率. 中国农业科学, 2019, 52: 4139-4153.

Gong X W, Dang K, Li J, Luo Y, Zhao G, Yang P, Gao X L, Gao J F, Wang P K, Feng B L. Effects of different intercropping patterns on photosynthesis production characteristics and water use efficiency of proso millet. Sci Agric Sin, 2019, 52: 4139-4153 (in Chinese with English abstract).

[22] 许大全. 气孔的不均匀关闭与光合作用的非气孔限制. 植物 生理学通讯, 1995, 31: 246-252.

Xu D Q. Non-uniform stomatal closure and non-stomatal limitation of photosynthesis. Plant Physiol Commun, 1995, 31: 246252 (in Chinese with English abstract).

[23] 王钰云, 王宏富, 李智, 段宏凯, 黄珊珊. 谷子花生间作对谷 子光合特性及产量的影响. 中国农业科技导报, 2020, 22: 153-165. 
Wang Y Y, Wang H F, Li Z, Duan H K, Huang S S. Influences of millet-peanut intercropping on photosynthetic characteristics and yield of millet. J Agri Sci Tec, 2020, 22: 153-165 (in Chinese with English abstract).

[24] 齐广平, 银敏华, 苏鹏海, 康燕霞, 李晓敏, 王金恒. 枸杞苜 宿间作模式下水分调控对枸杞光合特性与水分利用的影响. 水土保持学报, 2019, 33: 242-248.

Qi G P, Yin M H, Su P H, Kang Y X, Li X M, Wang J H. Effects of water regulation on photosynthetic characteristics and water use of Lycium barbarum under the mode of intercropping alfalfa and Lycium barbarum. J Soil Water Conser, 2019, 33: 242-248 (in Chinese with English abstract).

[25] 张吉旺, 董树亭, 王空军, 胡昌浩, 刘鹏. 大田遮荫对夏玉米 光合特性的影响. 作物学报, 2007, 33: 216-222.

Zhang J W, Dong S T, Wang K J, Hu C H, Liu P. Effects of nitrogen application regimes on yield, quality, and nitrogen use efficiency of super japonica hybrid rice. Acta Agron Sin, 2007, 33: 216-222 (in Chinese with English abstract).

[26] 苏本营, 宋艳霞, 陈圣宾, 杨文钰. 大豆幼苗对套作玉米遮荫 环境的光合生理生态响应. 生态学报, 2015, 35: 3298-3308.
Su B Y, Song Y X, Chen S B, Yang W Y. Photosynthetic responses of soybean (Glycine max) seedlings to shading caused by maize in an intercropping system. Chin $J$ Eco, 2015, 35: 3298-3308 (in Chinese with English abstract).

[27] 邹长明, 王允青, 曹卫东, 刘英, 张晓红, 唐杉. 不同品种小 豆光合作用和生长发育对弱光的响应. 应用生态学报, 2015, 26: 3687-3692.

Zou C M, Wang Y Q, Cao W D, Liu Y, Zhang X H, Tang B. Response of photosynthesis and growth to weak light regime in different Adzuki bean (Vigna angularis) varieties. Chin J Appl Eco, 2015, 26: 3687-3692 (in Chinese with English abstract).

[28] Zhang F S, Li L. Using competitive and facilitative interactions in intercropping systems enhances crop productivity and nutrient-use efficiency. Plant and Soil, 2003, 248: 305-312.

[29] 刘广才, 杨祁峰, 李隆, 孙建好. 小麦/玉米间作优势及地 上部与地下部因素的相对贡献. 植物生态学报, 2008,32 : 477-484.

Liu G C, Yang Q F, Li L, Sun J H. Intercropping advantage and contribution of above- and below-ground. Chin J Plant Eco, 2008, 32: 477-484 (in Chinese with English abstract). 